\title{
Texting at a Child Helpline: How Text Volume, Session Length and Duration, Response Latency, and Waiting Time Are Associated with Counseling Impact
}

\author{
Trine Natasja Sindahl, $\mathrm{PhD}^{1}$ and Willemijn van Dolen, $\mathrm{PhD}^{2}$
}

\begin{abstract}
This study investigated the association between formal features, such as text volume, session length and duration, response latency, and waiting time, and the impact of counseling. The analysis was based on 603 text message counseling sessions at a child helpline and connected information about the formal features of the sessions and the effects on clients. The results showed that sessions characterized by more text volume from the counselor in each message, but with fewer messages from beginning to end, were more effective than sessions without these characteristics. Furthermore, session duration was associated with a positive impact, whereas counselor response latency was not. This indicates that clients might benefit from the asynchronous affordance of texting as long as the counselor responds promptly and with dense messages. We also found that the impact measured at end of session predicted the impact measured 2 weeks after the child or young person received counseling.
\end{abstract}

Keywords: child helpline, counseling impact, SMS counseling, text messaging counseling, mediated communication in counseling

\section{Introduction}

$\mathbf{C}$

HILD HELPLINES USE technology to provide young people with confidential access to someone who listens and an opportunity to be heard ${ }^{1}$; in addition, they offer a safe, confidential, and accessible reporting mechanism for children suffering from violence and abuse. ${ }^{2}$ In 2016, there were more than 24 million instances of contact between child helplines and young people globally ${ }^{3}$; this included more than half a million counseling sessions via SMS, which is this the second most common method (after telephone counseling) for providing children with help. ${ }^{3}$ However, despite its growing importance, the influence of the SMS service format on children's experience of the helplines is unknown.

This study examined the formal features ${ }^{4}$ of dialoguebased, human-handled, text message counseling and explored the importance of these characteristics to counseling impact, measured as the client's experience of being heard, changes in well-being, and empowerment in line with previous research exploring child helplines. ${ }^{5-8}$

\section{Formal features of text message counseling}

While research has focused primarily on automated text services, ${ }^{9}$ dialogue-based counseling through text messages within the helpline context remains virtually unexplored. Therefore, our literature review was based on research in the context of chat and telephone counseling, which resemble text message counseling in that they are all mediated and dialogue-based and can be provided in an anonymous manner. Chat and text message counseling also share the characteristic of being text-based. However, while telephone and synchronous chat counseling require the client and counselor to be in front of their computers or tablets or on the phone at the same time, text message communication does not require the presence. ${ }^{10-14}$ This creates a different affordance for elements such as session length and text mass.

Texting has the possibility of being both (almost) synchronous and asynchronous. ${ }^{15}$ Because of this, certain concepts, such as time, pauses, and waiting, are particularly interesting variables. We refer to these concepts as the formal features of texting.

\footnotetext{
${ }^{1}$ Department of Psychology, University of Copenhagen, Copenhagen, Denmark

${ }^{2}$ International Strategy \& Marketing, University of Amsterdam Business School, Amsterdam, Netherlands.
} 
Counselor response length. Response length was defined as the average number of characters sent by the counselor per message within a session (many messages had typing errors, such as missing or added spaces, which made automatic word counting less precise than counting characters). Through text, the counselor can actively show the child that he or she has listened and understands. ${ }^{16}$ Therefore, we expected longer messages to be associated with a positive impact on children.

Counselor response latency. Communicating in writing is much slower than oral conversations, even when synchronous. ${ }^{6,7,13,14,17-20}$ This creates inevitable response latencies $^{21}$ as children spend time putting thoughts into writing and again when counselors do the same. While both counselors and children have mentioned that having time to write and edit one's thoughts is an advantage of text-based counseling, $4,13,14,17$ it might not have the same positive effect when waiting for a reply. Suler ${ }^{14}$ suggested that an advantage of synchronous therapy is the therapist's effort to be with the client in real time as a sign of commitment and dedication, which creates the experience of presence. ${ }^{22}$ Latency on the counselor's side might be interpreted by the child as lacking this characteristic.

Waiting time. We know from studies of service quality that waiting time can result in negative responses, such as boredom, irritation, anxiety, tension, and helplessness. ${ }^{22-24}$ We expect this negative response to waiting to be particularly strong when experienced by a help-seeking child.

Session duration. Fukkink and Hermanns ${ }^{6}$ suggested that, for child helpline chat and telephone services, session duration may be positively associated with increased wellbeing. However, a recent study on chat counseling at a child helpline showed a negative relationship between changes in well-being and session duration on children seeking emotional support, presumably because of exposure to negative emotions for too long and a lack of capacity to process the session. ${ }^{25}$ Texting enables children to reflect and respond when convenient, and not having to cope with counselors' immediate reactions might be considered positive by children writing about emotional and personal issues. ${ }^{14}$ The asynchronicity of texting makes it possible for children to have increased power over the pace of the sessions, resulting in longer sessions.

Session length. While time might challenge children's cognitive capacity in synchronous counseling, in asynchronous counseling, the session length, measured as the total number of messages exchanged, might be the important variable. We identified only one study that assessed the effects of session length measured as the number of messages (or "turns") ). ${ }^{26}$ In this study of a peer counseling chat service, a positive relationship was found between length and rated quality. ${ }^{26} \mathrm{~A}$ possible strength of text counseling (as opposed to synchronous chat) is that children will have the dialogue present on their mobile phones after a session has ended and can return to and reread it. Sessions with fewer messages might provide children with a better overview of the counseling process compared with long threads.

In summary, we hypothesized that counseling impact would be positively associated with longer but fewer messages from counselors, longer session duration, and shorter response latency and waiting time (Fig. 1):

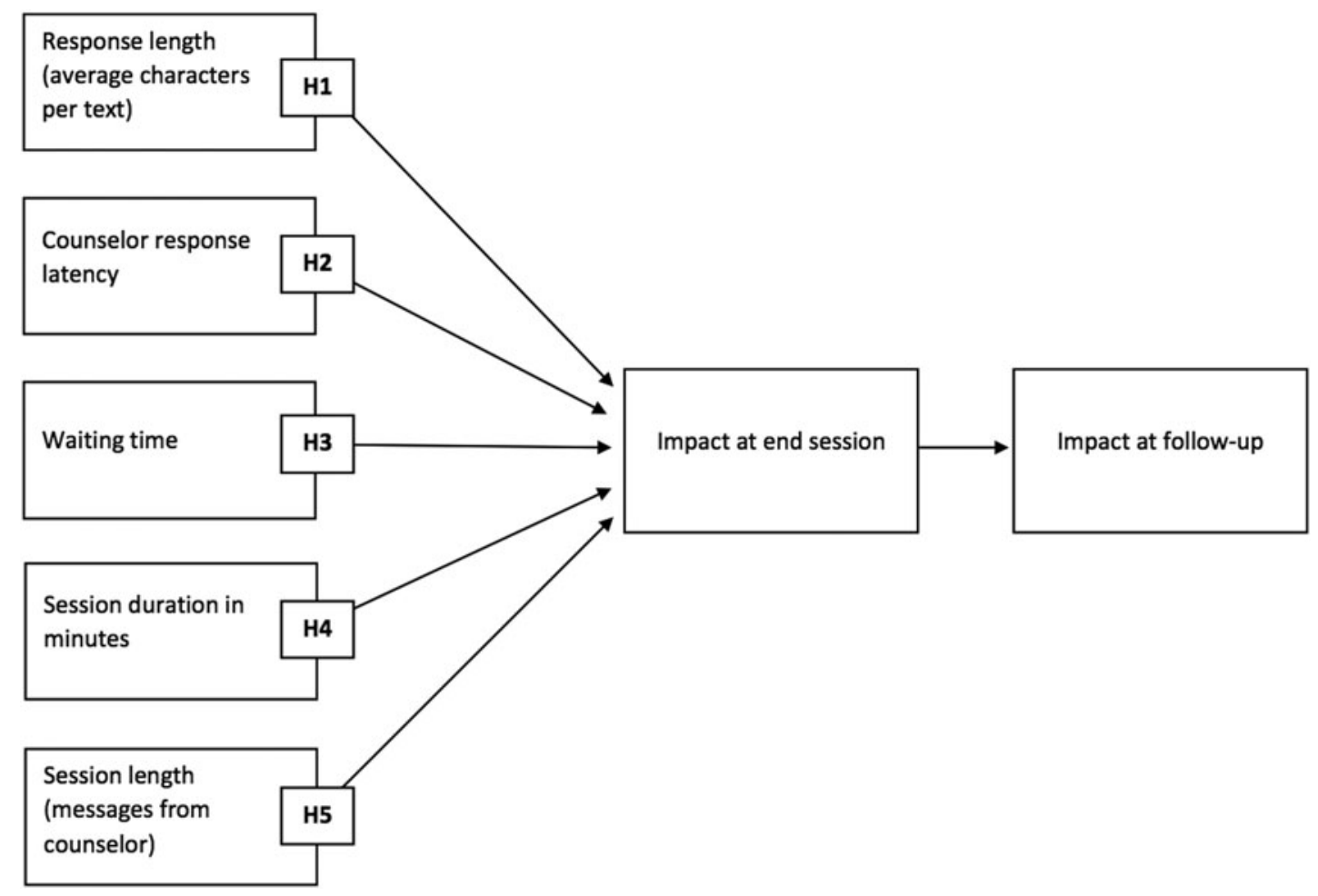

FIG. 1. Conceptual model. 
H1: Longer counselor responses will be associated with positive counseling impact.

H2: Shorter counselor response latency will be associated with positive counseling impact.

H3: Shorter waiting time before the session will be associated with positive counseling impact.

H4: Longer session duration will be associated with positive counseling impact.

H5: A lower number of messages from the counselor (session length) will be associated with positive counseling impact.

\section{Materials and Methods}

\section{The Danish child helpline}

The data were collected at the Danish child helpline, BørneTelefonen, which responds to people younger than 23 years. The helpline is accessible online and through the common European child helpline number 116111 and is open 365 days a year from 11:00 a.m. until 2:00 a.m. It is staffed by 450 trained volunteers, all with professional backgrounds in child work. Children contact the helpline with a variety of issues (Table 1).

\section{Sample}

Data were collected between June 14, 2015, and June 14, 2016. During this period, all youths using the texting service, where a counselor had ended the session, were presented with an automated text with a link to an online questionnaire. The present study included all sessions $(N=603)$ with children who completed the End-Session Questionnaire (EQ) and the Followup Questionnaire (FQ) 2 weeks after receiving counseling. The FQ was sent only to children who provided active consent in the EQ.

Sample characteristics were compared with the characteristics of all sessions (Table 1). A goodness-of-fit chi-squared test revealed that our participants were significantly younger $\left[\chi^{2}(3)=20.98, p<0.001\right]$ compared with the population, and we found an overrepresentation of sessions concerning family relationships and an underrepresentation of sessions about body issues, health, sex, and sexuality $\left[\chi^{2}(8)=24.37, p<0.01\right]$. We did not observe significant differences according to sex or experience of using the helpline.

\section{Data Sets and Instruments}

The data set consisted of client-descriptive variables, formal features of the sessions, and clients' survey responses. Data sets were merged via a unique user ID for each session, making it possible to collect and merge the data without compromising the client's anonymity. The counselor records, completed after each session, provided information about the clients' sex, age, and reasons for contact. The child helpline's text counseling system provided information on waiting time, latency time, text volume, and session time (Table 2).

\section{Table 1. Descriptive Statistics and Participants}

\begin{tabular}{|c|c|c|c|c|c|}
\hline & \multicolumn{2}{|c|}{$\begin{array}{l}\text { Included } \\
(\mathrm{N}=603)\end{array}$} & \multicolumn{2}{|c|}{$\begin{array}{l}\text { All sessions } \\
(\mathrm{N}=6,060)\end{array}$} & \multirow[b]{2}{*}{$\chi^{2}$} \\
\hline & $\mathrm{n}$ & $\%$ & $\mathrm{n}$ & $\%$ & \\
\hline Sex & & & & & 2.96 \\
\hline Boy & 58 & 9.6 & 718 & 11.8 & \\
\hline Girl & 543 & 90.0 & 5,326 & 87.9 & \\
\hline Unknown & 2 & 0.3 & 16 & 0.3 & \\
\hline Age, years & & & & & $20.98 * * *$ \\
\hline $9-12$ & 237 & 39.3 & 1,564 & 26.2 & \\
\hline $13-14$ & 198 & 33.1 & 1,945 & 32.5 & \\
\hline $15-17$ & 139 & 23.2 & 1,993 & 33.3 & \\
\hline $18+$ & 24 & 4.0 & 478 & 8.0 & \\
\hline User experience $^{\mathrm{a}}$ & & & & & 3.46 \\
\hline First time & 293 & 48.8 & 847 & 47.0 & \\
\hline Recurrent (1-3 previous sessions) & 175 & 29.2 & 522 & 29.0 & \\
\hline Experienced (4-10 previous sessions) & 74 & 12.3 & 270 & 15.0 & \\
\hline Very experienced ( $>10$ previous sessions) & 58 & 9.7 & 164 & 9.1 & \\
\hline Reason for contact $^{\mathrm{b}}$ & & & & & $24.37 * *$ \\
\hline Family relationships & 85 & 14.1 & 637 & 10.5 & \\
\hline Abuse and violence & 44 & 7.3 & 452 & 7.5 & \\
\hline Problems in regard to the authorities & 3 & 0.5 & 60 & 1.0 & \\
\hline Body and health & 58 & 9.6 & 731 & 12.1 & \\
\hline Psychosocial mental health & 143 & 23.7 & 1,287 & 21.2 & \\
\hline Peer relationships & 187 & 31.0 & 1,820 & 30.0 & \\
\hline School-related issues & 11 & 1.8 & 174 & 2.9 & \\
\hline Sex and sexuality & 26 & 4.3 & 455 & 7.5 & \\
\hline Other & 46 & 7.6 & 444 & 7.3 & \\
\hline
\end{tabular}

${ }^{\mathrm{a}}$ Reported by the child.

${ }^{\mathrm{b}}$ Reported by counselor. Only one reason can be chosen.

$* * * p<0.001, * * p<0.01$. 
Table 2. Predictor Variables

\begin{tabular}{|c|c|}
\hline Variable name & Definition \\
\hline $\begin{array}{l}\text { Counselor response } \\
\text { length }\end{array}$ & $\begin{array}{l}\text { Average number of characters per message by the counselor in session. Calculated as the total } \\
\text { number of characters by the counselor divided by the total number of messages by counselor. }\end{array}$ \\
\hline $\begin{array}{l}\text { Counselor response } \\
\text { latency }\end{array}$ & $\begin{array}{l}\text { Average time from when the child sends a message in an active session until the counselor } \\
\text { replies. When the child sends multiple messages, the latency time is calculated from the first } \\
\text { message until the last reply from the counselor. }\end{array}$ \\
\hline Waiting time & $\begin{array}{l}\text { Minutes from when the child sends a second message to the helpline (replying to an automated } \\
\text { text received after the first message was sent) until the counselor sends the first message back. }\end{array}$ \\
\hline Session duration & $\begin{array}{l}\text { Minutes elapsed from the first message from the counselor (defining the session start) until } \\
\text { the counselor technically ends the session by sending an automated text to the child (defining } \\
\text { the session end). }\end{array}$ \\
\hline Session length & $\begin{array}{l}\text { Number of messages the counselor sends to the child from the beginning to the end of the } \\
\text { session. }\end{array}$ \\
\hline
\end{tabular}

\section{Child survey}

Assessing the impact of anonymous, mediated counseling is challenging, ${ }^{27-29}$ but the technology used for text message counseling has opened ways of distributing questionnaires while still acknowledging children's need for informed consent and anonymity. Impact data were collected through an online questionnaire using IBM Data Collection Interviewer Server Administration Version 6.

In the EQ, we measured the clients' experience of counseling impact from the beginning to the end of each session. Impact was measured using seven items. Three were adapted from previous studies on child helpline outcomes" ${ }^{5,6}$ (1) "When talking to BørneTelefonen, I ... (wasn't/was) taken seriously," (2) "Did it help talking to BørneTelefonen? (Not at all/A lot)," and (3) "After talking to BørneTelefonen, I feel ... (much worse/much better)." One item was developed for the purpose of this study: (4) "In the session with BørneTelefonen, we ... (did/didn't) talk about what I wanted." One item was adapted from the Session Impact Scale ${ }^{30}$ and the Youth Counseling Impact Scale ${ }^{31}$ and has been applied in several impact studies of child helplines ${ }^{5,6,8}$ : (5) "After talking to BørneTelefonen, I have ... (no idea/an idea) about what to do." One item was adapted from the Strengths and Difficulties Questionnaire (SDQ P11-17 Followup) ${ }^{32}$ : (6) "After talking to BørneTelefonen, the problem is ... (much worse/solved)." The last item was adapted from an impact study of the Swedish child helpline": (7) "After talking to BørneTelefonen, I have more trust in myself (disagree/agree)."

In the FQ, we measured the clients' perceived counseling impact from the time they contacted the helpline to the time of followup ( 2 weeks later). FQ impact was measured using four items repeated from the EQ (items 2, 3, 6, and 7). One item was added to measure agency adapted from the Youth Counseling Impact Scale ${ }^{31}$ : "Have you tried any of the things you discussed with BørneTelefonen? (None/All of them)." The period of 2 weeks between the end of counseling and followup was chosen to ensure that the children would be able to recall the session and the issues raised in the session would still be relevant.

Each question was rated on a five-point smiley scale with statements at each end of the scale (e.g., ranging from 1 ["It didn't help at all"] to 5 ["It helped a lot"]). In accordance with recommendations for surveying children, a smiley scale was chosen with a frowning smiley at 1 , a neutral smiley at 3 , and a smiling smiley at $5 .^{33}$ Internal consistency for each of the scales was good to excellent based on examination using Cronbach's alpha, which was 0.91 for the EQ and 0.86 for the FQ.

\section{Data Analysis and Results}

\section{Sample characteristics}

The sample consisted of 603 SMS-mediated counseling sessions; $90 \%$ of the participants were girls, and participants' mean age was 13.2 years $(S D=2.6)$. Half of the respondents were first-time users of the service, whereas $10 \%$ had used the SMS service at least 10 times before (Table 1).

Regarding the formal features of the session, counselors' text messages had an average response length of 189 characters per message (range: 40-741, Table 3). The average insession response latency was 5.4 minutes, and the average waiting time before the session was activated by a counselor was 90.4 minutes (range: $<1$ minute to $>24$ hours 52 minutes; the latter being clients who did not receive responses within the opening hours on the same day). The average session duration was 2 hours and 50 minutes (range: 4 minutes to 47 hours 11 minutes). An average session included 13.4 messages from the counselor (range: 2-78).

The end-session survey results showed that in $84.9 \%$ $(n=512)$ of the included sessions, children or young people

Table 3. Descriptive Statistics on Formal Features $(N=603)$

\begin{tabular}{|c|c|c|c|c|c|}
\hline & Min & $\operatorname{Max}$ & Median & M & SD \\
\hline Response length & 40 characters & 741 characters & 172 characters & 189 characters & 91.0 \\
\hline Response latency & $<1$ minute & 2 hours 4 minutes & 3 minutes & 5.4 minutes & 10.0 \\
\hline Waiting time & $<1$ minute & 24 hours 52 minutes & 19 minutes & 1 hour 30 minutes & 239.4 \\
\hline Session duration & 4 minutes & 47 hours 11 minutes & 1 hour 9 minutes & 2 hours 50 minutes & 330.5 \\
\hline Session length & 2 messages & 78 messages & 11 messages & 13.4 messages & 8.83 \\
\hline
\end{tabular}

$\mathrm{SD}$, standard deviation. 
Table 4. Counseling Impact $(N=603)$

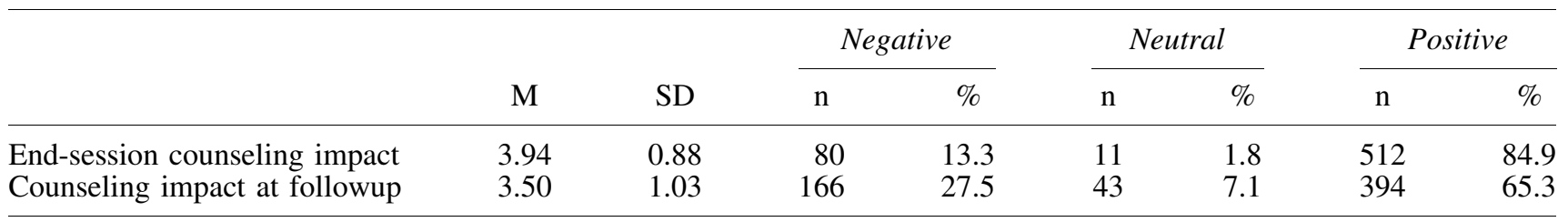

experienced an immediate positive impact after the session (Table 4). At 2-week followup, this number dropped to $65.3 \%$ $(n=394)$.

\section{Test of structural model}

Structural equation modeling with maximum likelihood estimation using AMOS 23 software was used to test our model. Response length, counselor response latency, waiting time, session duration, and session length were treated as exogenous variables; End-session impact and impact at followup were considered endogenous variables. Age and sex were included as control variables. The correlations between the variables are presented in Table 5.

The adequacy of the model was assessed using several common fit indices, ${ }^{34}$ which indicated a good to acceptable fit (comparative fit index $=0.98, \chi^{2}=23.47$, root mean square error of approximation $=0.08,90 \%$ confidence interval $=0.05$ 0.11 , Bollen's incremental fit index $=0.98$, standardized root mean square residual $=0.02$ ) between the hypothesized model and the data. ${ }^{35}$ The standardized coefficients for the model are shown in Figure 2.

The estimated coefficients showed that counselor response length was significantly associated with end-session impact, and counselor response latency was significantly negatively associated with end-session impact. Therefore, H1 and H2 were accepted. Waiting time was significantly negatively related to impact. Consequently, H3 was accepted. Counseling session duration was significantly positively associated with end-session impact. Therefore, H4 was accepted. Session length, measured as the number of messages from the counselor, was negatively associated with end-session impact. Therefore, H5 was accepted. The results also showed that the clients' perception of the impact of counseling at the end session was a positive predictor of counseling impact at followup.

Regarding the control variables ${ }^{36}$ (age and sex), age influenced the relationships between the exogenous and endogenous variables, whereas sex did not. Age was negatively related to impact, indicating that older users of the helpline service experienced a less positive counseling impact relative to that of younger service users.

\section{Discussion}

We found an overall positive counseling impact immediately after the session and 2 weeks later, which is similar to previous study results regarding child helpline telephone, chat, and e-mail services, ${ }^{5-8,13,25,37,38}$ indicating that using text messages as a medium in child helpline counseling may provide similar results to other more commonly researched modalities, but comparative studies are needed to confirm this.

Sessions characterized by fewer messages (H5) from the counselor and more characters per message (H1) were associated with a positive influence on help-seeking clients. The idea that text interactions should consist of many ${ }^{39}$ brief $^{40}$ messages does not seem to apply here. Perhaps communicating via fewer more substantial messages provides the child with a better overview of the session content. Our findings indicating that counselors need to be expressive and elaborate in their writing stand in contrast to research on synchronous chat, wherein a large text shared by the counselor was found to have a negative relationship to the child's immediate well-being after seeking emotional support from the helpline. ${ }^{25}$

In addition, the results showed that session duration (H4) and length (H5) were quite different features in text messaging. ${ }^{10-12,15}$ Sessions can be long in duration but short in message quantity and vice versa. Duration exerted a positive relationship and the number of messages exerted a negative relationship with counseling impact. Research on synchronous chat counseling has shown inconsistent results concerning the effects of session duration. ${ }^{6,17,25}$ A long duration with few texts indicates that the correspondence is quite asynchronous, and based on the current study results, this asynchronicity does not seem to be a limitation and could be a strength of text message communication. Asynchronicity affords greater control over when and how

Table 5. Correlation Table

\begin{tabular}{lcccccccc}
\hline & Age & Sex & $\begin{array}{c}\text { Response } \\
\text { length }\end{array}$ & $\begin{array}{c}\text { Response } \\
\text { latency }\end{array}$ & $\begin{array}{c}\text { Waiting } \\
\text { time }\end{array}$ & Duration & $\begin{array}{c}\text { Session } \\
\text { length }\end{array}$ & $E Q$ \\
\hline Sex & $-0.12^{* * *}$ & & & & & & & \\
Response length & $-0.13^{* *}$ & -0.02 & & & & & & \\
Response latency & -0.03 & -0.00 & $-0.13^{* *}$ & & & & & \\
Waiting time & -0.07 & -0.01 & -0.02 & -0.03 & & & & \\
Duration & -0.00 & -0.04 & -0.04 & $-0.64 * * *$ & $-0.14^{* * *}$ & & & \\
Session length & $-0.16^{* * *}$ & -0.04 & $-0.19^{* * *}$ & -0.03 & -0.02 & $-0.32^{* * *}$ & & \\
EQ & $-0.20^{* * *}$ & -0.08 & $-0.16^{* *}$ & -0.03 & -0.05 & -0.00 & $-0.23^{* * *}$ & \\
FQ & $-0.22^{* * *}$ & -0.06 & -0.04 & -0.04 & -0.01 & -0.01 & $-0.27^{* * *}$ & $0.58^{* * *}$ \\
\hline
\end{tabular}

$* * * p<0.001, * * p<0.01$.

EQ, End-Session Questionnaire; FQ, Followup Questionnaire 


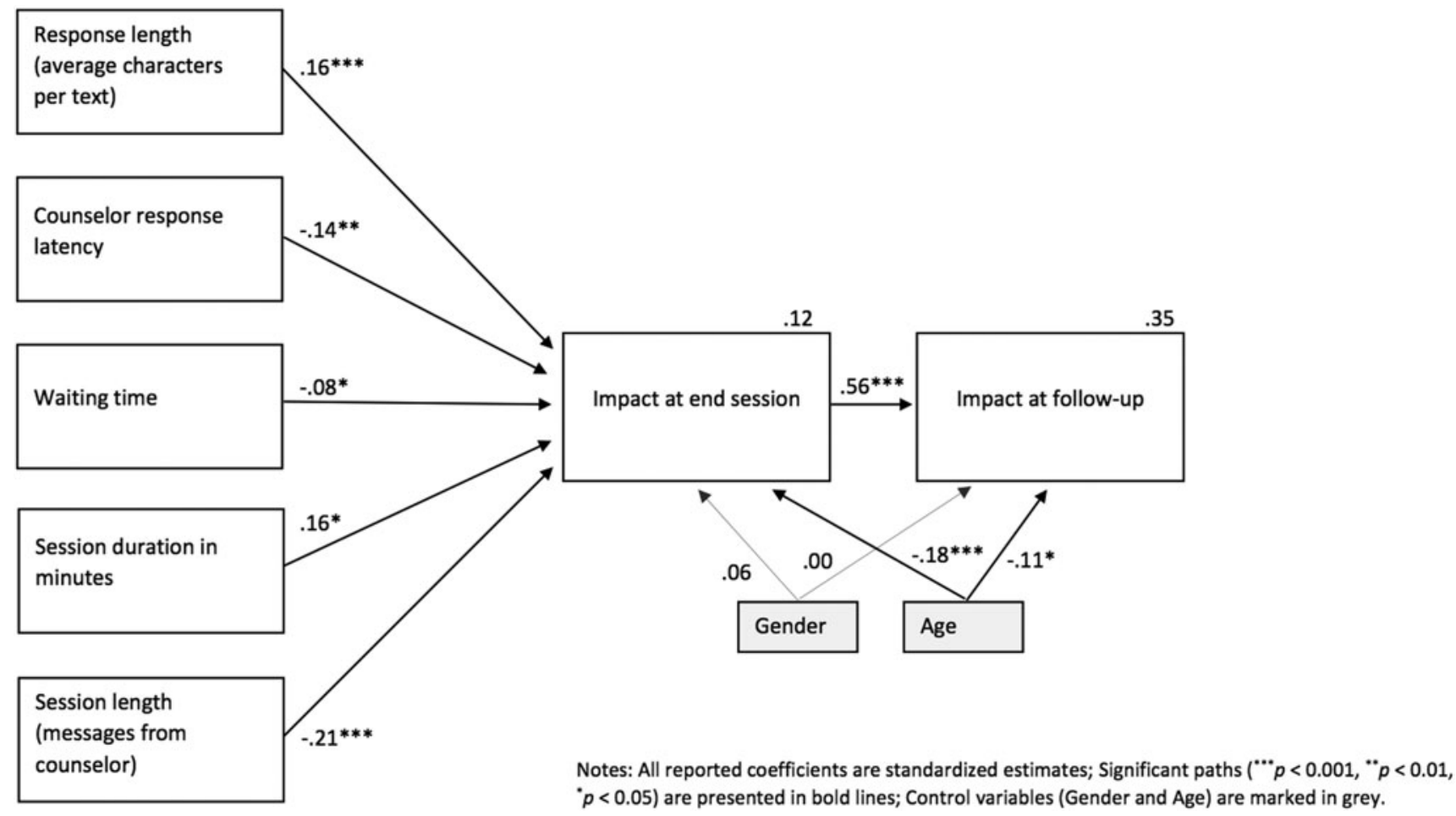

FIG. 2. Summary of results.

to respond to messages, leaving reflection time and greater face management. ${ }^{14,41,42}$

Within text counseling, children and counselors can communicate across contexts ${ }^{43}$ and challenge the idea that the presence is determined by physical space ${ }^{44}$ or synchronicity. Texting makes the counseling service highly accessible and promises the possibility of contact with a counselor whenever required, conveniently and from a variety of self-selected locations. $^{13,41}$ Our results highlight the benefits of this.

However, although we observed a positive association between impact and session duration, counselors should not prolong the session duration by taking extra time to respond to children. Our results showed that response latency (H2) on the counselors' side is associated with a lower counseling impact. As stated by Kalman et al. ${ }^{45(\mathrm{p} 12)}$ : "In asynchronous CMC, a quick response is one of the only non-verbal tools that can be used to signal immediacy, care, and presence." Latency may be effective for the person producing a response but not for the one waiting for it. $^{14,46}$ In addition, we observed a negative relationship between counseling impact and waiting time before counseling (H3) in accordance with our hypothesis. Previous research has shown that increased waiting time can result in negative responses. ${ }^{23}$

The present study was the first to examine how formal features of text message counseling relate to impact on children and youth seeking help from a child helpline. The child helpline under study provided a suitable context for conducting this research, as it has a strong tradition of data collection, has invested in technology that can support this type of research, and has a high degree of awareness and use among the youth population. However, there may be cultural differences that challenge the generalizability of our findings to helplines in other parts of the world. Further studies on these differences are encouraged.

The present study focused solely on factors influenced by counselors' behavior. However, further research exploring both counselors' and children's behavior, with particular consideration of linguistic style matching, is required. ${ }^{47}$

Text message or SMS counseling can be conducted in many ways. It can be a one-text-one-answer type of service or based on automated texts without any counselor involvement. ${ }^{9}$ Different modalities set different conditions to provide support to the helpline service users. ${ }^{16}$ When texting, the counselor is silent, invisible, and because of the asynchronicity of this format, absent. The affordance of texting offers both possibilities and constraints. ${ }^{48}$ The results of the current study show that, for services offering dialogue-based, human-handled, text counseling sessions should entail fewer and longer messages over a longer period, with quick responses from the counselor to increase probability of a positive effects on children.

\section{Acknowledgments}

The authors wish to thank Børns Vilkår, Trygfonden, Innovation Fund Denmark, children and counselors at the Danish child helpline, Charlotte Smerup, Winnie Laerkelund Hansen, and Torben Bechmann-Jensen for helping with and supporting this research.

\section{Author Disclosure Statement}

No competing financial interests exist. 


\section{Funding Information}

The project is externally funded via a public foundation (Innovation Fund Denmark) and a private foundation (Trygfonden). The research was part of an industrial $\mathrm{PhD}$ project and the first author was, at the time of the data collection, formally employed at the Danish child helpline.

\section{References}

1. The United Nations. (1989) Convention on the rights of the child. Treaty Series, Vol. 1577. New York: The United Nations, p. 3.

2. European Commission. (2015) 9th European forum on the rights of the child - coordination and cooperation in integrated child protection systems. Reflection paper. http://ec .europa.eu/justice/fundamental-rights/files/2015_forum_ roc_background_en.pdf (accessed Oct. 15, 2016).

3. Child Helpline International. (2017) We listen to the voices of children and young people. https://www.childhelpline international.org/wp-content/uploads/2017/11/WeListen.pdf (accessed July 15, 2018).

4. Neuendorf KA. (2002) The content analysis guidebook. California: SAGE Publications.

5. Andersson K, Osvaldsson K. (2012) Utvärdering av BRIS Internetbaserade stödkontakter [Evaluation of BRIS Internetbased support contacts]. Research report on childhood and the study of children. Sweden: University of Linköping.

6. Fukkink RG, Hermanns JMA. Children's experiences with chat support and telephone support. Journal of Child Psychology and Psychiatry 2009; 50:759-766.

7. Fukkink R, Hermanns J. Counseling children at a helpline: chatting or calling? Journal of Community Psychology 2009; 37:939-948.

8. King R, Bambling M, Reid W, et al. Telephone and online counselling for young people: a naturalistic comparison of session outcome, session impact and therapeutic alliance. Counselling and Psychotherapy Research 2006; 6:175-181.

9. Spohr SA, Nandy R, Gandhiraj D, et al. Efficacy of SMS text message interventions for smoking cessation: a metaanalysis. Journal of Substance Abuse Treatment 2015; 56: $1-10$.

10. Castelnuovo G, Gaggioli A, Mantovani F, et al. From psychotherapy to e-therapy: the integration of traditional techniques and new communication tools in clinical settings. Cyberpsychology \& Behavior 2003; 6:375-382.

11. Frehner C. (2008) Email, SMS, MMS, the linguistic creativity of asynchronous discourse in the new media age. Linguistic insights, Vol. 58. Bern New York: Peter Lang.

12. Helles R. (2009) Personlige medier i hverdagslivet [Personal medias in everyday life]. Copenhagen: Faculty of Humanities, University of Copenhagen.

13. Sindahl T. (2013) Chat counselling for children and youtha handbook. Amsterdam: Child Helpline International.

14. Suler J. Psychotherapy in cyberspace: a 5-dimensional model of online and computer-mediated psychotherapy. Cyberpsychology \& Behavior 2000; 3:151-159.

15. Goumi A, Volckaert-Legrier O, Bert-Erboul A, et al. SMS length and function: a comparative study of 13- to 18-yearold girls and boys. (Report). Revue Europeenne De Psychologie Appliquee 2011; 4:175.

16. Danby S, Butler C, Emmison M. When 'listeners can't talk': comparing active listening in opening sequences of telephone and online counseling. Australian Journal of Communication 2009; 2:1-23.
17. Bambling M, King R, Reid W, et al. Online counselling: the experience of counsellors providing synchronous single-session counselling to young people. Counselling and Psychotherapy Research 2008; 8:110-116.

18. Reid W, Caswell D. (2005) A national telephone and online counselling service for young Australians. In Batch J, Wootton R, eds. Telepediatrics: telemedicine and child health. London: Royal Society of Medicine Press, pp. 169187.

19. Schalken F, ed. (2008) Handbook for implementing online counselling-setting up a child helpline via the Internet. Amsterdam: Child Helpline International.

20. Tidwell LC, Walther JB. Computer-mediated communication effects on disclosure, impressions, and interpersonal evaluations: getting to know one another a bit at a time. Human Communication Research 2002; 28:317-348.

21. King R, Bambling M, Lloyd C, et al. Online counselling: the motives and experiences of young people who choose the Internet instead of face to face or telephone counselling. Counselling and Psychotherapy Research 2006; 3:169-174.

22. Park E, Sundar S. Can synchronicity and visual modality enhance social presence in mobile messaging? Computers in Human Behavior 2015; 45:121-128.

23. Carmon Z, Shanthikumar JG, Carmon TF. A psychological perspective on service segmentation models: the significance of accounting for consumers' perceptions of waiting and service. Management Science 1995; 11:1806-1815.

24. Mattila A, Mount D. The impact of selected customer characteristics and response time on E-complaint satisfaction and return intent. International Journal of Hospitality Management 2003; 2:135-145.

25. van Dolen WM, Weinberg C, Ma L. (2016) Are you listening? An empirical investigation of an IT-mediated helpline. Presented at the 14th International Research Conference in Service Management, La Londe les Maures, France.

26. Fukkink R. Peer counseling in an online chat service: a content analysis of social support. Cyberpsychology, Behavior and Social Networking 2011; 14:247-251.

27. Mishara B, Daigle M. Effects of different telephone intervention styles with suicidal callers at two suicide prevention centers: an empirical investigation. American Journal of Community Psychology 1997; 25:861-885.

28. Mishara B, Chagnon F, Daigle M, et al. Which helper behaviors and intervention styles are related to better shortterm outcomes in telephone crisis intervention? Results from a silent monitoring study of calls to the U.S. 1-800SUICIDE Network. Suicide and Life-Threatening Behavior 2007; 37:308-321.

29. Mishara BL, Côté LP. (2014) Suicide prevention and new technologies: towards evidence based practice. In Mishara BL, Kerkhof AJK, eds. Suicide prevention and new technologiesevidence based practice. UK: Palgrave Macmillan, pp. 1-23.

30. Elliott R, Wexler MM. Measuring the impact of sessions in process-experiential therapy of depression: the session impacts scale. Journal of Counseling Psychology 1994; 2:166-174.

31. Riemer M, Kearns MA. Description and psychometric evaluation of the Youth Counseling Impact Scale. Psychological Assessment 2010; 22:259-268.

32. Goodman, R. (n.d.) SDQ-S11-17 FOLLOW UP. www .sdqinfo.org/py/sdqinfo/b3.py?language $=$ Danish $\quad$ (accessed June 15, 2016).

33. de Leeuw, ED. (2011) Improving data quality when surveying children and adolescents: cognitive and social development and its role in questionnaire construction and 
pretesting. Utrecht, the Netherlands: Utrecht University. www.aka.fi/globalassets/awanhat/documents/tiedostot/lapset/ presentations-of-the-annual-seminar-10-12-may-2011/sur veying-children-and-adolescents_de-leeuw.pdf (accessed Dec. 10, 2017).

34. Byrne, B. (2012) Structural equation modeling with Mplus, basic concepts, applications, and programming. Multivariate applications series. New York, N.Y: Routledge.

35. Hu L, Bentler PM. Cutoff criteria for fit indexes in covariance structure analysis: conventional criteria versus new alternatives. Structural Equation Modeling 1999; 1:1-55.

36. Westland, J. (2015) Structural equation models, from paths to networks. Studies in systems, decision and control. Cham: Springer.

37. King R, Nurcombe B, Bickman L, et al. Telephone counselling for adolescent suicide prevention: changes in suicidality and mental state from beginning to end of a counselling session. Suicide \& Life-threatening Behavior 2003; 33:400411.

38. van Dolen WM, Weinberg C. Child helplines: how social support and controllability influence service quality and well-being. Journal of Services Marketing 2017; 31:385396.

39. Powell P, Roberts J. Situational determinants of cognitive, affective, and compassionate empathy in naturalistic digital interactions. Computers in Human Behavior 2017; 68:137148.

40. Walsh E, Brinker J. Short and Sweet? Length and informative content of open-ended responses using SMS as a research mode. Journal of Computer-Mediated Communication 2016; 1:87-100.

41. Gibson K, Cartwright C. Young people's experiences of mobile phone text counselling: balancing connection and control. Children and Youth Services Review 2014; 43:96104.
42. Thurlow C, Brown A. (2003) Generation txt? The sociolinguistics of young people's text-messaging. Discourse Analysis Online. http://extra.shu.ac.uk/daol/articles/v1/n1/ a3/thurlow2002003-01.html (accessed Jan. 29, 2018).

43. Helles R. Hverdagslivets nye medier [New media in everyday life]. Dansk Sociologi 2011; 21:49-63.

44. Gergen K (2003) Self and community in the new floating worlds. In Nyíri K, ed. Mobile democracy, essays on society, self and politics (Communications in the 21st century). Vienna: Passagen Verlag, pp. 103-114.

45. Kalman Y, Ravid G, Raban D, et al. Pauses and response latencies: a chronemic analysis of asynchronous CMC. Journal of Computer-Mediated Communication 2006; 1: $1-23$.

46. Seo M, Kim J, Yang H. Frequent interaction and fast feedback predict perceived social support: using crawled and self-reported data of Facebook users. Journal of Computer-Mediated Communication 2016; 4:282-297.

47. Niederhoffer K, Pennebaker J. Linguistic style matching in social interaction. Journal of Language and Social Psychology 2002; 21:337-360.

48. Hutchby I. (2001) Conversation and technology: from the telephone to the Internet. Malden, MA: Polity Press.

Address correspondence to: Dr. Trine Natasja Sindahl Department of Psychology University of Copenhagen $\emptyset$ ster Farimagsgade $2 A$ Copenhagen 1353 Denmark

E-mail: trine.sindahl@psy.ku.dk 